Rev. Inst. Flor. v. 28 n. 1. p. 37-47 jun. 2016

http://dx.doi.org/10.4322/rif.2016.002

ISSN impresso 0103-2674/on-line 2178-5031

\title{
COBERTURA DE LIANAS NO DOSSEL FLORESTAL E SEUS EFEITOS SOBRE A REGENERAÇÃO DE ESPÉCIES ARBÓREAS ${ }^{1}$
}

\section{LIANA'S COVERTURE IN THE FOREST CANOPY AND ITS EFFECTS ON REGENERATION OF TREE SPECIES}

\author{
Marcele Almeida da SILVA² \\ Mariane Martins RODRIGUES²; Ciro Abbud RIGHI'³
}

\begin{abstract}
RESUMO - A regeneração natural é um bom indicador da capacidade de perpetuação das espécies arbóreas e da manutenção da biodiversidade em fragmentos florestais. $\mathrm{O}$ estado de conservação desses remanescentes está diretamente relacionado ao seu tamanho, tipo de vizinhança e grau de perturbação. A abundância de lianas vem sendo apontada como um indicador de degradação afetando diretamente a regeneração natural. Desse modo, é importante a avaliação da presença e cobertura de lianas no dossel das árvores e verificar sua influência na regeneração natural. Neste estudo, avaliou-se a participação das lianas na cobertura do dossel de uma Floresta Estacional Semidecidual inserida em uma matriz de pastagem, procurando relacioná-la com a regeneração natural. Para avaliar essa regeneração foram instalados e avaliados doze transectos radiais perpendiculares à borda do fragmento. Observou-se que as maiores densidades de regeneração foram encontradas nas áreas em que a cobertura do dossel estava acima de $80 \%$, independentemente de sua composição (lianas ou árvores), indicando que a cobertura por lianas também contribui positivamente para o desenvolvimento dos regenerantes.
\end{abstract}

Palavras-chave: fragmento florestal; Floresta Estacional Semidecidual; efeito de borda.

\begin{abstract}
Natural regeneration is a good indicator of the perpetuation capacity and maintenance of biodiversity in forest fragments. The state of conservation of forest fragments is directly related to its size, neighborhood type and degree of disturbance. The abundance of lianas has been identified as an indicator of degradation directly affecting the natural regeneration. Thus, it is important to evaluate liana's presence and cover in the canopy of trees and verify its influence on the natural regeneration. In this study it was evaluated the participation of lianas in the canopy cover of a Seasonal Semideciduous Forest inserted in a grassland matrix and its relationship to natural regeneration. To evaluate this regeneration it were installed and evaluated twelve transects perpendicular to the edge with the pasture. The results showed that the highest regeneration densities were found in the areas where the canopy cover was over $80 \%$ regardless of their composition (lianas or trees), indicating that the lianas's cover also contributes positively to the development of regenerants.
\end{abstract}

Keywords: forest fragment; Seasonal Semideciduous Forest; edge effect.

\footnotetext{
${ }^{1}$ Recebido para análise em 03.11.2015. Aceito para publicação em 06.05.2016.

2Universidade de São Paulo, Escola Superior de Agricultura "Luiz de Queiroz" - ESALQ, Departamento de Ciências Florestais, Av. Pádua Dias, 11, 13418-900 Piracicaba, SP, Brasil.

${ }^{3}$ Autor para correspondência: Ciro Abbud Righi - ciro@usp.br
} 
SILVA, M.A. da et al. Cobertura de lianas e os efeitos sobre a regeneração de espécies arbóreas.

\section{INTRODUÇÃO}

A Mata Atlântica era considerada uma das maiores florestas tropicais existentes no planeta. O bioma originalmente abrangia uma área de 1,3 milhões $\mathrm{km}^{2}$, restando atualmente apenas $8,5 \%$ de sua área, a qual está restrita a pequenos e esparsos fragmentos (Fundação SOS Mata Atlântica - SOSMA, 2014). Dada à extensão da degradação e de sua biodiversidade, a Mata Attântica é considerada um dos cinco principais hotspots mundiais para a conservação (WWF, 2015). De acordo com o estudo do Instituto Nacional de Pesquisas Espaciais - INPE em parceria com a Fundação SOS Mata Atlântica (SOSMA e INPE, 2015), existem cerca de 230 mil fragmentos defloresta com áreas entre 3 e 100 ha. Segundo Ribeiro et al. (2009), a maior parte dos fragmentos de Mata Atlântica (83\% do total) possui área de até 50 ha, estando localizados preponderantemente em propriedades privadas.

Durante toda a trajetória de desenvolvimento do Brasil, a Mata Atlântica foi sendo sistematicamente desmatada e substituída pela agricultura. Apesar de sua importância, o bioma sofreu severamente com a pressão de ocupação de novas áreas para culturas e com a ocupação humana desordenada (Villani, 2007). Atualmente, a Mata Atlântica acolhe os mais significativos polos industriais, agrícolas e urbanos (Pinto et al., 2006) do país. Cerca de $60 \%$ da população brasileira reside em áreas originalmente da Mata Atlântica, gerando cerca de $70 \%$ do PIB nacional (Rodrigues et al., 2009). No Estado de São Paulo, ocorreu um avanço acelerado na supressão das florestas nos últimos 100 anos (Carvalho, 2007), sendo que apenas 17,5\% do território paulista está coberto por vegetação nativa. Isso corresponde a uma área de 4,34 milhões ha cobertos por campos e florestas em diferentes estágios de conservação (Sistema de Informações Florestais do Estado de São Paulo - SIFESP, 2010). Além disso, os grandes remanescentes dessas florestas possuem pouca ou nenhuma conexão com os demais fragmentos, os quais estão inseridos em uma paisagem modificada, em geral imersos em matrizes predominantemente agrícolas (Ribeiro et al., 2009).

A fragmentação de habitats decorre da subdivisão de uma região devido principalmente às atividades humanas - perturbações naturais e eventos climáticos extremos também podem causar a separação de indivíduos de uma população (Dale e Pearson, 1997).
A divisão da floresta em pequenos pedaços, distantes uns dos outros, acarreta mudanças microclimáticas em sua borda, tais como: maior incidência de luz; menor índice de umidade e maior densidade de plantas do que o interior do fragmento florestal. Quanto mais antiga a borda, maior a diferença na composição de espécies entre a borda e o interior (Rodrigues, 1998). Tais variações favorecem o crescimento de plantas que conseguem se desenvolver nessas novas condições, causando mudanças na composição florística original da floresta (Viana e Pinheiro, 1998). O exemplo mais comum dessas plantas "oportunistas" são algumas espécies de lianas, definidas como plantas escaladoras que germinam no chão, mas perdem a capacidade de se sustentar à medida que crescem. Por isso, as lianas necessitam de um suporte físico externo para alcançar o dossel da floresta (Gerwing et al., 2006). Por outro lado, ao se desenvolverem, também atuam como apoio para outros indivíduos, facilitando o acesso destes ao dossel superior (Putz et al., 1984; Campanello et al., 2007). Ao atingirem o dossel, as lianas se desenvolvem abundantemente, entrelaçando-se nas copas das árvores (Putz e Windsor, 1987) e aumentando a competição por luz, água e nutrientes (Gentry, 1991; Tabarelli e Mantovani, 2000).

O crescimento de lianas nos dosséis florestais é um fenômeno natural. A maioria das árvores presentes em florestas tropicais e subtropicais é colonizada por lianas (Campanello et al., 2012). Em fragmentos conservados, tais trepadeiras apresentam considerável riqueza de espécies, sendo responsáveis por cerca de $11 \%$ da diversidade vegetal dos remanescentes de Mata Atlântica (Udulutsch et al., 2004). Entretanto, em fragmentos degradados as lianas tornam-se hiperabundantes (Laurance et al., 2001), comprometendo a regeneração natural das espécies arbóreas (Jordão, 2009). A elevada densidade desse grupo pode restringir os processos naturais de sucessão secundária (Girão, 2015) na medida em que diminuem o crescimento em altura das árvores jovens, prejudicando seu desenvolvimento (Putz et al., 1984). Assim como apontado por César (2014), o entendimento acerca da cobertura de lianas hiperabundantes e seus efeitos sobre o remanescente florestal é essencial para o desenvolvimento de metodologias de conservação. 
SILVA, M.A. da et al. Cobertura de lianas e os efeitos sobre a regeneração de espécies arbóreas.

O grau de cobertura do dossel também é um parâmetro que deve ser considerado na avaliação do estado de conservação de um fragmento. A cobertura proporcionada pelas copas das árvores influencia diretamente no tipo de vegetação do sub-bosque devido às mudanças provocadas no ambiente físico. Assim, a composição florística e a distribuição espacial das espécies também depende do grau de interação com o estrato arbóreo (Jardim et al., 2007). Estudos sugerem que espécies arbóreas teriam suas distribuições relacionadas às aberturas de clareiras no dossel florestal (Denslow, 1980). Segundo Gandolfi et al. (2007), uma importante função do dossel é a criação e manutenção de microssítios particulares de regeneração. $\mathrm{O}$ estabelecimento de condições ideais, como radiação amena e alta umidade relativa etc., irá favorecer o desenvolvimento das plântulas (Jardim et. al., 2007) que irão garantir a perpetuação da vegetação (Toledo-Aceves, 2014).

A compreensão da dinâmica da regeneração natural é importante visto que possibilita estimativas de parâmetros populacionais das árvores (Pereira et al., 2001), podendo-se inferir o estado de conservação e perpetuação do fragmento em resposta ao manejo empregado (Amador e Viana, 2000; Daniel e Jankauskis, 1989). Segundo Vieira (1996), a regeneração das espécies depende da dispersão de propágulos (frutos, sementes, bulbos etc.), do banco de sementes presente no solo e do banco de plântulas. Estes dois últimos são as principais fontes encontradas em ambientes perturbados responsáveis pela recolonização da vegetação (Schmitz, 1992). Segundo Saunders et al. (1991) e Nascimento et al. (2010), é necessário desenvolver estratégias de conservação florestal visando minimizar os efeitos negativos da fragmentação florestal e prever a magnitude dos efeitos de borda e sua extensão dentro dos remanescentes.

Nesse sentido, é importante avaliar o estado da regeneração dos remanescentes florestais e relacioná-los ao grau de cobertura do dossel. Nesse estudo, objetivou-se avaliar a cobertura do dossel florestal e a participação de lianas, relacionando-as à regeneração natural das espécies arbóreas.

\section{MATERIAL E MÉTODOS}

\subsection{Caracterização da Área}

Este estudo foi conduzido em um fragmento florestal denominado "Mata da Pedreira", com área de 14 ha, localizado dentro do campus da Escola Superior de Agricultura "Luiz de Queiroz" Universidade de São Paulo, em Piracicaba-SP $\left(22^{\circ} 42^{\prime} 40^{\prime \prime} \mathrm{S}\right.$ e $\left.47^{\circ} 37^{\prime} 30^{\prime \prime} \mathrm{W}\right)$. Na face noroeste desse fragmento, localiza-se uma pastagem composta por Brachiaria decumbens (capim braquiária), a qual é mantida com cerca de $30 \mathrm{~cm}$ de altura. A porção sudeste da mata faceia o ribeirão Piracicamirim, sendo esta relativamente bem preservada (Figura 1).

A vegetação natural da área é classificada no Sistema Fitogeográfico Brasileiro como Floresta Estacional Semidecídua (Instituto Brasileiro de Geografia e Estatística - IBGE, 1992). O clima local é subtropical úmido, com verão quente e chuvoso e inverno seco, correspondendo a Cwa na classificação de Köppen (1948). Os solos são eutróficos, originários da decomposição de rochas basálticas (Catharino, 1989). A precipitação anual é de $1.278 \mathrm{~mm}$, sendo $1.000 \mathrm{~mm}$ de outubro a março e $278 \mathrm{~mm}$ de abril até setembro. O balanço hídrico indica uma escassez de água de $213 \mathrm{~mm}$ no período seco e um excesso de $234 \mathrm{~mm}$ no período chuvoso. A temperatura média anual é de $21,4{ }^{\circ} \mathrm{C}$ com temperatura média mensal de $24,8{ }^{\circ} \mathrm{C}$ no verão e de $17,1^{\circ} \mathrm{C}$ no inverno (Sentelhas et al., 1998).

A Mata da Pedreira é considerada o maior e mais importante remanescente florestal original de Mata Atlântica da região de Piracicaba, detentora de alta diversidade de fauna e flora (Catharino, 1989). Apesar disso, o remanescente apresenta áreas em diferentes estágios de degradação devido às pressões externas em função do uso da terra de seu entorno, como pastos, culturas agrícolas anuais e áreas abertas (André et al., 2010 - dados não publicados $)^{4}$. Além desses fatores degradantes, existem também estradas de acesso e cercas que cortam a Mata (César, 2014). 
SILVA, M.A. da et al. Cobertura de lianas e os efeitos sobre a regeneração de espécies arbóreas.

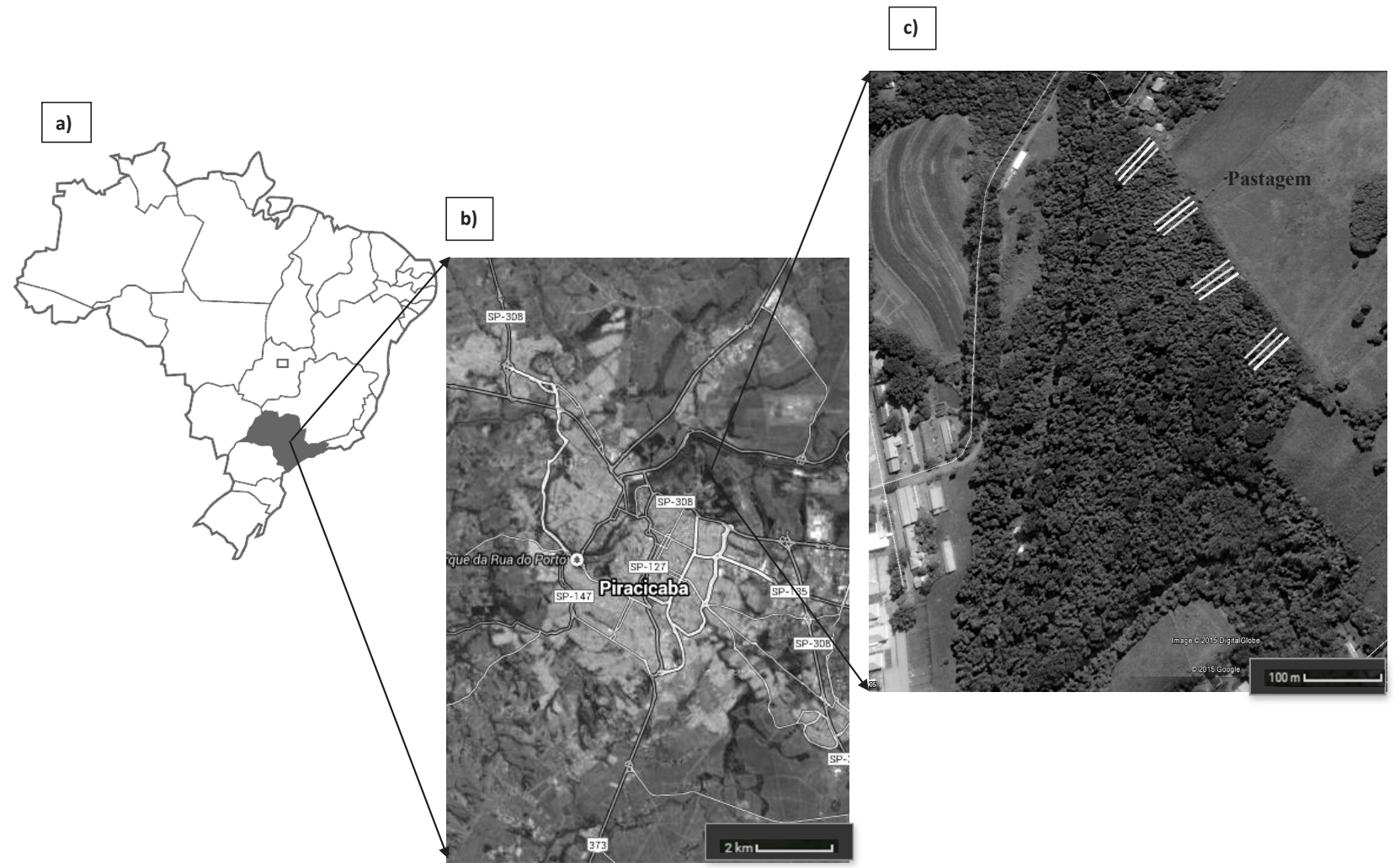

Figura 1. Vista aérea do fragmento de Floresta Estacional Semidecidual - Mata da Pedreira, localizada no campus "Luiz de Queiroz" - ESALQ-USP, em Piracicaba, SP. As linhas brancas na figura "c" indicam os locais de instalação dos transectos. Fonte: Google Maps. Acesso em: 6 mar. 2015.

Figure 1. Aerial view of Seasonal Semideciduous Forest fragment - Mata da Pedreira, located on the campus "Luiz de Queiroz" - ESALQ-USP in Piracicaba, SP. White lines in the figure "c" indicate the positions of the transects. Source: Google Maps. Access on: 6 March 2015.

No histórico de perturbação da Mata da Pedreira, encontram-se relatos de incêndios na área. Segundo os funcionários mais antigos do local, o último incêndio foi registrado em 1981, configurando-se como o principal agente de degradação do fragmento. $\mathrm{O}$ evento atingiu grande parte da mata, reduzindo algumas áreas a solo exposto com grande quantidade de troncos carbonizados (Catharino, 1989). Assim, gramíneas e lianas hiperabundantes colonizaram a área, sufocando as espécies arbóreas nativas e dificultando a regeneração natural (Ducatti et al., 20095 - dados não publicados; André et al., 2010 - dados não publicados).

\subsection{Avaliação da Estrutura Florestal, Cobertura do Dossel e Regeneração Natural}

Neste trabalho, considerou-se como regeneração natural o conjunto de indivíduos arbóreos em estágio inicial de desenvolvimento com até um metro de altura. Para avaliar essa regeneração, foram instalados doze transectos perpendiculares à borda com dimensões de 1 x $50 \mathrm{~m}$ (subdivididos em 5 parcelas de 1 x $10 \mathrm{~m}$ ) - verificar na Figura 1 sua disposição aproximada. Os transectos foram instalados perpendicularmente à borda da mata que faceia a pastagem, sendo distribuídos de modo sistemático em toda sua extensão, da seguinte forma: os doze transectos foram divididos em quatro trios equidistantes $(50 \mathrm{~m})$, paralelamente uns aos outros, e em cada grupo os transectos foram colocados a uma distância de $10 \mathrm{~m}$ entre si (Figura 1). 
SILVA, M.A. da et al. Cobertura de lianas e os efeitos sobre a regeneração de espécies arbóreas.

No transecto central de cada trio, as medidas foram ampliadas para $10 \times 50 \mathrm{~m}$ sendo avaliado o grau de cobertura do dossel e classificada a participação de lianas. A avaliação da cobertura do dossel foi realizada com o auxílio de um quadro reticulado de $50 \times 50 \mathrm{~cm}$, o qual possui um plástico transparente divido em 100 quadrículas de $5 \mathrm{~cm}^{2}$ cada. Esse método é recomendado por Poggiani et al. (1996), e foi empregado também nos trabalhos de Carvalho (2007), Duarte (2008 dados não publicados) ${ }^{6}$ e Lima et al. (2012). $\mathrm{O}$ método baseia-se na contagem do número de quadrículas que contenham folhas em $50 \%$ ou mais da área de cada quadrícula. A partir disso, é possível obter uma estimativa da cobertura do dossel diretamente em porcentagem. Em cada subparcela $(10 \times 10 \mathrm{~m})$, foi escolhido um ponto amostral em sua área central, realizando-se um total de cinco contagens em cada ponto, da seguinte maneira: com o quadro reticulado na posição horizontal com os braços esticados acima da cabeça (cerca de $2 \mathrm{~m}$ do solo), sendo feita a primeira contagem e após isso realizadas mais quatro medições em direções ortogonais, segurando-se o quadro com uma inclinação de cerca de $45^{\circ}$. Com os dados das cinco repetições calculou-se a média, que é o índice de cobertura expresso em porcentagem para aquele ponto. Para calcular o índice de cobertura da área total, calcula-se a média dos resultados obtidos nos diversos pontos amostrados (Poggiani et al., 1996).

Nas mesmas posições de avaliação do dossel, foi estimada visualmente a porcentagem com que as lianas contribuíam para o seu fechamento. Tal estimativa baseou-se na observação do padrão foliar encontrado e da presença de seus caules característicos, tanto no dossel como no interior da mata. A participação das lianas no total da cobertura do dossel foi classificada seguindo as aproximações de $0 \%, 25 \%, 50 \%, 75 \%$ ou $100 \%$ em cada subparcela, de acordo com o método adotado por Tabanez et al. (1992).
A estrutura vertical e horizontal da vegetação dos quatro maiores transectos $-\mathrm{T}_{1} ; \mathrm{T}_{2} ; \mathrm{T}_{3}$ e $\mathrm{T}_{4}(10 \times 50 \mathrm{~m})$ foi analisada sendo representada em perfis vegetacionais horizontais e verticais. Todas as espécies florestais maiores ou iguais a $5 \mathrm{~cm}$ de diâmetro à altura do peito (DAP medido a 1,3 $\mathrm{m}$ de altura) foram marcadas, registrando-se a posição de cada árvore utilizando-se as coordenadas $\mathrm{X}$ e Y. As variáveis medidas foram: i) altura total da árvore, definida como a distância do solo até o topo da copa; ii) altura do tronco, definida como a distância entre o solo e a inserção do primeiro galho, e iii) as dimensões horizontais da copa, medida por trena seguindo os quatro pontos cardeais. Esses dados foram utilizados para a construção dos perfis vertical e horizontal de cada transecto em papel milimetrado, sendo, posteriormente, passados a nanquim em papel vegetal (escala 1:100 cm).

\section{RESULTADOS E DISCUSSÃO}

A Mata da Pedreira apresenta um dossel irregular (González, 2013), com a predominância de indivíduos de espécies em estágio inicial de sucessão e uma minoria de indivíduos em estágios mais avançados (Catharino, 1989). Segundo Silva (2012), existe alta densidade de poucas espécies na Mata, tais como Bauhinia forficata e Urera baccifera, que representaram, respectivamente, 213 ind.ha ${ }^{-1} \mathrm{e}$ 153 ind.ha $^{-1}$. Ainda segundo essa autora, foi encontrada grande densidade de pioneiras (de $56 \%$ a $86 \%$ ) e baixa riqueza de espécies arbóreas (de 11 a 16) até os $50 \mathrm{~m}$ da borda, sendo estes indicativos de perturbação a que floresta está sujeita.

Os perfis horizontal e vertical dos quatro transectos radiais avaliados em função da distância da borda (de 0 até $50 \mathrm{~m}$ em direção ao centro do fragmento) podem ser visualizados na Figura 2. Nesses diagramas, é possível observar as diferenças estruturais da floresta, a condição atual de cobertura total e por lianas, e a distribuição de indivíduos arbóreos em função da distância da borda em cada uma das parcelas avaliadas. 
SILVA, M.A. da et al. Cobertura de lianas e os efeitos sobre a regeneração de espécies arbóreas.
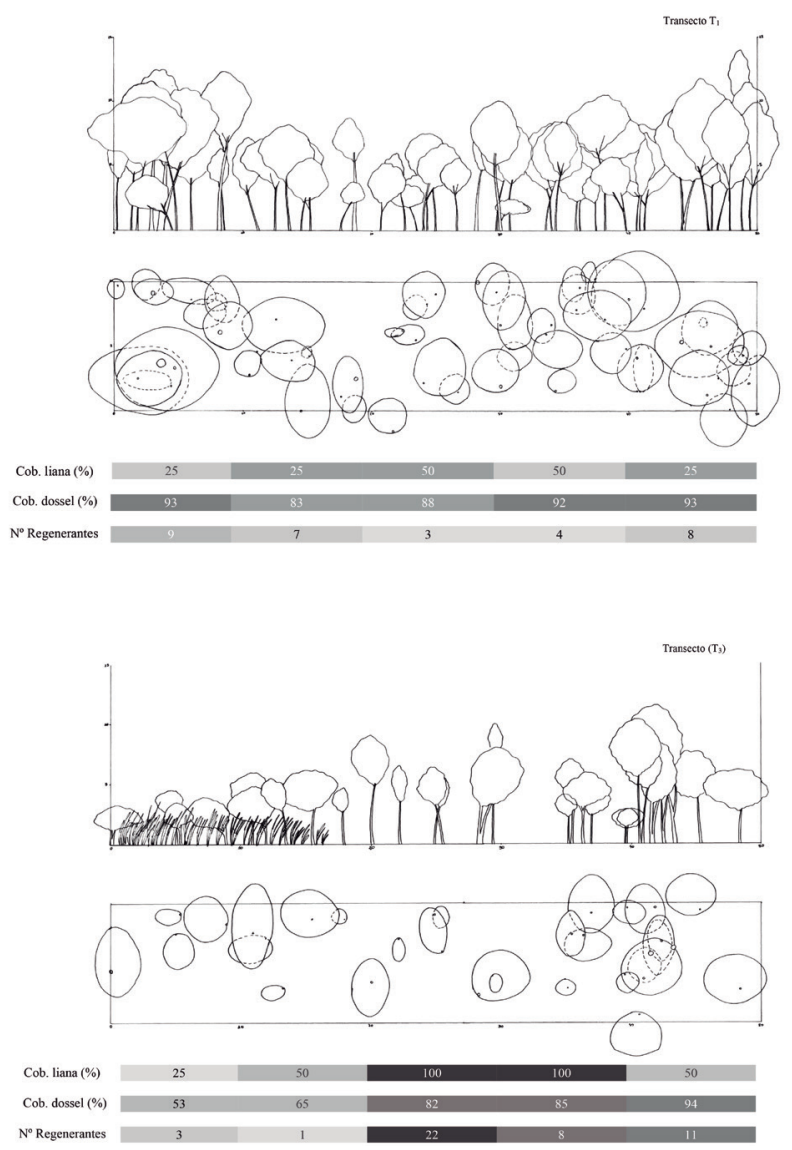
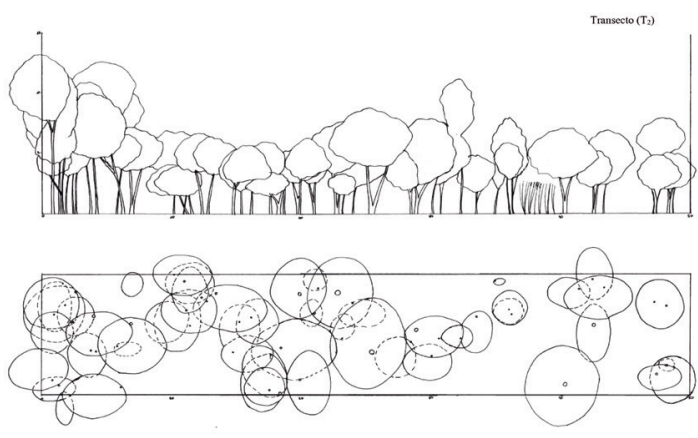

Cob. liana (\%)

Cob. dossel (\%)
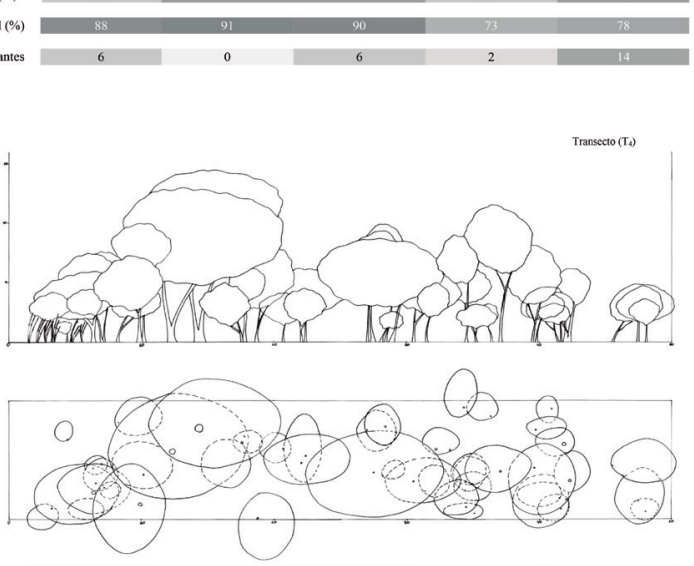

Cob. liana (\%)

Cob. dossel (\%)

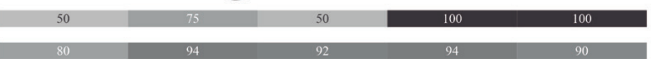

Nº Regenerantes

Figura 2. Perfis horizontal e vertical dos transectos $\mathrm{T}_{1} ; \mathrm{T}_{2} ; \mathrm{T}_{3}$ e $\mathrm{T}_{4}$ em fragmento de Floresta Estacional Semidecidual Mata da Pedreira, localizada no campus "Luiz de Queiroz" - ESALQ-USP em Piracicaba, SP. Os dados de cobertura por lianas e cobertura do dossel foram coletados e mesclados ao perfil de cada transecto e estão representados por barras em escala de cinza imediatamente abaixo de cada desenho esquemático. Quanto maior o valor de cobertura, maior a intensidade de cinza. A borda do fragmento está à esquerda do desenho.

Figure 2. Horizontal and vertical profiles transects $T_{1} ; T_{2} ; T_{3}$ and $T_{4}$ in Seasonal Semideciduous Forest fragment Mata da Pedreira, located on the campus "Luiz de Queiroz" - ESALQ-USP in Piracicaba, SP. Coverage data by lianas and canopy cover were collected and merged to the profile of each transect and are represented by grayscale bars immediately below each schematic drawing. The greater the amount of coverage, the greater the intensity of gray. The forest edge is located at the left of the drawing. 
SILVA, M.A. da et al. Cobertura de lianas e os efeitos sobre a regeneração de espécies arbóreas.

O capim braquiária esteve presente em três dos quatro transectos denotando a grande entrada de radiação solar nestas porções. Em $\mathrm{T}_{2}$, foi observada a presença de gramíneas na seção mais interior avaliada $(40-50 \mathrm{~m})$; em $\mathrm{T}_{3}$, foi observada sua presença apenas na faixa inicial do transecto, nas seções $0-10 \mathrm{~m}$ e 10-20 m, e em $\mathrm{T}_{4}$, apenas na primeira seção $(0-10 \mathrm{~m})$. Segundo Urbanetz et al. (2003), espécies invasoras, como o capim braquiária, alteram padrões de riqueza, abundância e biomassa entre a borda e o interior do fragmento. Desse modo, seu controle é muito importante tanto em trabalhos de restauração como para a manutenção do funcionamento das florestas naturais.

Em três dos quatro transectos, a cobertura por lianas superou a porcentagem de cobertura das copas das árvores a diferentes distâncias da borda. $\mathrm{O}$ transecto $\mathrm{T}_{3}$ destacou-se como o mais degradado, tanto pelo número reduzido de indivíduos arbóreos, principalmente nos primeiros $20 \mathrm{~m}$ da borda, quanto pela maior cobertura por lianas. Nesse transecto, foi observada tendência de aumento em altura da floresta de forma contínua. Além disso, em $T_{3}$ foi observado também o menor número de regenerantes até os $20 \mathrm{~m}$ da borda.

Aparentemente, nas seções em que a cobertura total (árvores e lianas) é alta, há maior número de regenerantes. $\mathrm{O}$ contrário é claramente percebido em $\mathrm{T}_{3}$, onde estavam presentes os menores valores de cobertura total associados à baixa regeneração. Na seção inicial de 0-10 m, o grau de cobertura total foi de $53 \%$, o menor valor registrado na área amostrada, acompanhado de apenas três regenerantes. Na seção de 10-20 m, a cobertura não ultrapassou os $65 \%$ e conteve somente um indivíduo regenerante.

Os resultados indicam que a cobertura por lianas também pode contribuir para o bom desenvolvimento de plântulas. Cansi (2007) em seu estudo observou uma relação significativa positiva entre a densidade de plântulas e a cobertura do dossel. Isso se deve ao fato de que as espécies de sub-bosque e demais espécies de sombra, características de florestas tropicais úmidas, necessitam de uma condição de maior sombreamento para que possam continuar fazendo parte da floresta (Santos et al., 2010).
Jordão (2009) conduziu seu estudo em uma Floresta Estacional Semidecidual vizinha a uma rodovia e observou que emaranhados de lianas pareciam manter um microambiente favorável ao ingresso de plântulas na borda do fragmento. O mesmo efeito foi encontrado por Savage (1992) ao comparar áreas infestadas por emaranhados de lianas e áreas com solo nu, constatando que o ambiente coberto por lianas foi mais favorável à regeneração de espécies arbóreas.

A regeneração natural é essencial para a conservação florestal em remanescentes na medida em que auxilia no processo de renovação da composição florística do local e na manutenção das espécies nativas (Huller et al., 2011). Além disso, as plântulas de espécies arbóreas de sub-bosque são diretamente afetadas por quaisquer alterações (naturais ou antrópicas) no dossel florestal. Assim, a caracterização florística e estrutural da regeneração natural é importante para as estratégias de manejo e conservação dos fragmentos (Martins e Rodrigues, 2002) e constitui um bom indicador de avaliação e monitoramento da restauração de ecossistemas degradados (Rodrigues e Gandolfi, 1998). Desse modo, seria conveniente que futuros trabalhos identificassem os regenerantes arbóreos presentes a fim se identificar quais grupos funcionais são favorecidos (e.g., pioneiras ou tolerantes à sombra).

\section{CONCLUSÕES}

Pôde-se observar que mesmo nas áreas em que a cobertura por lianas era alta houve um número significativo de regenerantes. As maiores densidades de regeneração arbórea foram encontradas nas áreas em que a cobertura do dossel estava acima de $80 \%$, independentemente de sua composição (lianas ou árvores). Desse modo, há indicações de que a cobertura por lianas também contribui positivamente para $\mathrm{o}$ desenvolvimento dos regenerantes. Entretanto, a avaliação dessa regeneração necessita ser acompanhada de maiores informações quanto às espécies e ao número de árvores jovens que conseguem ultrapassar a barreira de lianas e alcançar a parte superior do dossel. Somente assim será possível estimar a taxa de sobrevivência dos indivíduos e a contribuição desses regenerantes para a formação de uma floresta madura. 
SILVA, M.A. da et al. Cobertura de lianas e os efeitos sobre a regeneração de espécies arbóreas.

\section{REFERÊNCIAS BIBLIOGRÁFICAS}

AMADOR, D.B.; VIANA, V.M. Dinâmica de "capoeiras baixas" na restauração de um fragmento florestal. Scientia Forestalis, n. 57, p. $69-85,2000$.

CAMPANELLO, P.I. et al. Lianas in a subtropical Atlantic Forest: host preference and tree growth. Forest Ecology and Management, v. 242, p. 250-259, 2007.

. et al. Liana abundance, tree crown infestation, and tree regeneration ten years after liana cutting in a subtropical forest. Forest Ecology and Management, v. 284, p. 213-221, 2012.

CANSI, M.M.F.A. Regeneração natural de espécies arbóreas em fragmentos de Mata Atlântica na APA da bacia do rio São João, Rio de Janeiro. 2007. 96 f. Dissertação (Mestrado em Ecologia e Recursos Naturais) - Universidade Estadual do Norte Fluminense, Rio de Janeiro.

CARVALHO, D.F. Café, ferrovias e crescimento populacional: o florescimento da região noroeste paulista. Histórica, n. 27, 2007. Disponível em: $<$ http://www.historica.arquivoestado.sp.gov.br/ materias/anteriores/edicao27/materia02/texto02.pdf $>$. Acesso em: 3 mar. 2015.

CARVALHO, R. Medição dos índices relativos de luz e cobertura do dossel em área de vegetação nativa, Goiânia - GO. 2007. 90 f. Dissertação (Mestrado em Ciências Agrárias) Faculdade de Agronomia e Medicina Veterinária, Universidade de Brasília, Brasília, DF.

CATHARINO, E.L.M. Estudos fisionômicosflorísticos e fitossociológicos em matas residuais secundárias no município de Piracicaba, São Paulo. 1989. 181 f. Dissertação (Mestrado em Ciências Biológicas) - Instituto de Biologia, Universidade Estadual de Campinas, Campinas.

CÉSAR, R.G. Lianas hiperabundantes como filtros ecológicos para a sucessão secundária em fragmentos florestais degradados. 2014. $103 \mathrm{f}$. Dissertação (Mestrado em Ciências) - Escola Superior de Agricultura "Luiz de Queiroz", Universidade de São Paulo, Piracicaba.
DALE, V.H.; PEARSON, S.M. Quantifying habitat fragmentation due to land use change in Amazonia. In: LAURANCE, W.F.; BIERREGAARD, R.O. (Ed.). Tropical forest remnants: ecology, management and conservation of fragmented communities. Chicago: The University of Chicago Press, 1997. p. 400-409.

DANIEL, O.; JANKAUSKIS, J. Avaliação de metodologia para o estudo do estoque de sementes do solo. IPEF - Série Técnica, v. 41-42, p. 18-26, 1989.

DENSLOW, J.S. Gap partitioning among tropical rainforest trees. Biotropica, v. 12, p. 47-55, 1980.

FUNDAÇÃO SOS MATA ATLÂNTICA - SOSMA. Florestas: a Mata Atlântica. 2014. Disponível em: $<$ http://www.sosma.org.br/>. Acesso em: 3 fev. 2015.

FUNDAÇÃO SOS MATA ATLÂNTICA- SOSMA; INSTITUTO NACIONAL DE PESQUISAS ESPACIAIS - INPE. Atlas dos remanescentes florestais da Mata Atlântica período 2013-2014 Relatório Técnico 2015. Disponível em: $<$ http://mapas.sosma.org.br/dados/\#>. Acesso em: 3 fev. 2015.

GANDOLFI, S.; JOLY, C.A.; RODRIGUES, R.R. Permeability - impermeability: canopy trees as biodiversity filters. Scientia Agricola, v. 64, n. 4, p. 433-438, 2007.

GENTRY, A.H. The distribution and evolution of climbing plants. In: PUTZ, F.E.; MOONEY, H.A. (Ed.). The biology of vines. Cambridge: Cambridge University Press, 1991. p. 3-49.

GERWING, J.J. et al. A standard protocol for liana censuses. Biotropica, v. 38, n. 2, p. 256-261, 2006. Disponível em: < https://pantherfile.uwm.edu/s1/www/ Gerwing_et_al2006.pdf $>$. Acesso em: 16 ago. 2015.

GIRÃO, V.J. Alterações iniciais na dinâmica de regeneração de um fragmento florestal degradado após manejo de trepadeiras superabundantes. 2015. 63 f. Dissertação (Mestrado em Ciências) Centro de Energia Nuclear na Agricultura, Escola Superior de Agricultura "Luiz de Queiroz", Universidade de São Paulo, Piracicaba. 
SILVA, M.A. da et al. Cobertura de lianas e os efeitos sobre a regeneração de espécies arbóreas.

GONZÁLEZ, A.D.V. Dendrocronologia de árvores de Tectona grandis L. e Pinus caribaea var. hondurensis Barr. et Golf de plantação da Mata da Pedreira, Campus da ESALQ-USP, Piracicaba, São Paulo. 2013. 142 f. Dissertação (Mestrado em Ciências) - Escola Superior de Agricultura "Luiz de Queiroz", Universidade de São Paulo, Piracicaba.

HULLER, A. et al. Regeneração natural do componente arbóreo e arbustivo do parque natural municipal de Santo Ângelo-RS. Revista da Sociedade Brasileira de Arborização Urbana, v. 6, n. 1, p. 25-35, 2011. Disponvel em: $<$ http://www.revsbau.esalq.usp.br/artigos_cientificos/ artigo119-publicacao.pdf $>$. Acesso em: 3 mar. 2015.

INSTITUTO BRASILEIRO DE GEOGRAFIA E ESTATÍSTICA - IBGE. Manual técnico da vegetação brasileira. Rio de Janeiro: Departamento de Recursos Naturais e Estudos Ambientais, 1992. 92 p. (Série Manuais Técnicos em Geociências, n. 1).

JARDIM, F.C.S.; SERRÃO, D.R.; NEMER, T.C. Efeito de diferentes tamanhos de clareiras, sobre o crescimento e a mortalidade de espécies arbóreas, em Moju-PA. Acta Amazonica, v. 37, n. 1, p. 37-48, 2007.

JORDÃO, S.M.S. Manejo de lianas em borda de floresta estacional Semidecidual e de cerradão, Santa Rita do Passa Quatro, São Paulo. 2009. 248 f. Tese (Doutorado em Ciências) - Escola Superior de Agricultura "Luiz de Queiroz", Universidade de São Paulo, Piracicaba.

KÖPPEN, W. Climatologia: con un estudio de los climas de la tierra. México: Fondo de Cultura Econômica, 1948. 479 p.

LAURANCE, W.F. et al. Rain forest fragmentation and the structure of Amazonian liana communities. Ecology, v. 82, n. 1, p. 105-116, 2001.
LIMA, N.L. et al. Medição dos índices relativos de luz e cobertura do dossel em área de vegetação nativa, Goiânia - GO. In: REUNIÃO ANUAL DA SOCIEDADE BRASILEIRA PARA O PROGRESSO DA CIÊNCIA, 64., 2012, São Luís. Anais... São Luís: SBPC, 2012. p. 2250.

MARTINS, S.V.; RODRIGUES, R.R. Gap-phase regeneration in a semideciduous mesophytic forest, south-eastern Brazil. Plant Ecology, v. 163, p. 51-62, 2002.

NASCIMENTO, M.I. et al. Eficácia de barreira de eucaliptos na contenção do efeito de borda em fragmento de floresta subtropical no estado de São Paulo, Brasil. Scientia Florestalis, v. 38, p. 191-203, 2010.

PEREIRA, I.M. et al. Regeneração natural em um remanescente de caatinga sob diferentes níveis de perturbação, no agreste paraibano. Acta bot. bras. v. 15, n. 3, p. 413-426, 2001. Disponível em: $<$ http://www.scielo.br/pdf/abb/v15n3/7584.pdf $>$. Acesso em: 16 ago. 2015.

PINTO, L.P. et al. Mata Atlântica brasileira: os desafios para conservação da biodiversidade de um hotspot mundial. In: ROCHA, C.F.D. et al. (Ed.). Biologia da conservação: esências. Rio de Janeiro: RiMa Editora, 2006. p. 91-118.

POGGIANI, F.; OLIVEIRA, R.E.; CUNHA, G.C. Práticas de ecologia florestal. Documentos Florestais, v. 16, p. 1-44, 1996.

PUTZ, F.E.; LEE, H.S.; GOH, R. Effects of post-felling silvicultural treatments on woody vines in Sarawak. Malaysian Forester, v. 47, n. 3, p. 214-226, 1984.

.; WINDSOR, D.M. Liana phenology on Barro Colorado Island, Panama. Biotropica, v. 19, n. 4, p. 334-341, 1987.

RIBEIRO, M.C. et al. The Brazilian Atlantic forest: how much is left, and how is the remaining forest distributed? Implications for conservation. Biological Conservation, v. 142, p. 1141-1153, 2009. 
SILVA, M.A. da et al. Cobertura de lianas e os efeitos sobre a regeneração de espécies arbóreas.

RODRIGUES, E. Efeito de borda em fragmentos de floresta. Cadernos de Biodiversidade, v. 1, p. 1-5, 1998.

RODRIGUES, R.R.; BRANCALION, P.H.S.; ISERNHAGEN, I. (Org.). Pacto pela restauração da Mata Atlântica: referencial dos conceitos e ações de restauração florestal. São Paulo: LERF/ ESALQ : Instituto BioAtlântica, 2009. 264 p.

.; GANDOLFI, S. Restauração de florestas tropicais: subsídios para uma definição metodológica e indicadores de avaliação e monitoramento. In: DIAS, L.E.; MELO, J.W.V. (Ed.). Recuperação de áreas degradadas, Viçosa-MG: SOBRADE/UFV, 1998. p. 203-215.

SANTOS, E.G.; FERRAZ, E.M.N.; ARAÚJO, E.L. Caracterização da regeneração natural em uma área antropizada da mata atlântica de Pernambuco. In: CONNEPI-CONGRESSO NORTE-NORDESTE DE PESQUISA E INOVAÇÃO, 5., 2010, Maceió. Disponível em: <http://connepi.ifal.edu.br/ocs/ index.php/connepi/CONNEPI2010/paper/viewFile/ 698/415>. Acesso em: 17 fev. 2015.

SAUNDERS, D.A.; HOBBS, R.J.; MARGULES, C.R. Biological consequences of ecosystem fragmentation: a review. Conservation Biology, v. 1, p. 18-35, 1991.

SAVAGE, M. Germination of forest species under an anthropogenic vine mosaic in western Samoa. Biotropica, v. 24, n. 3, p. 460-462, 1992.

SCHMITZ, M.C. Banco de sementes no solo em áreas do reservatório da UHE Paraibuna. In: KAGEYAMA, P.Y. Recomposição da vegetação com espécies arbóreas nativas em reservatórios de usinas hidrelétricas da CESP. IPEF-Série Técnica, v. 8, n. 25, p. 7-8, 1992.

SENTELHAS, P.C. et al. Análise dos dados climáticos e do balanço hídrico climatológico de Piracicaba (1917-1997). Piracicaba: DFM/ ESALQ/USP, 1998. 81 p.
SILVA, M.A. Uso múltiplo do entorno de fragmentos florestais - a agrossilvicultura como forma de produção e proteção. Relatório científico Fapesp. Piracicaba, 2012.

SISTEMA DE INFORMAÇÕES FLORESTAIS DO ESTADO DE SÃO PAULO - SIFESP. 2010. Disponível em: <http://www.iflorestal.sp.gov.br/ sifesp/index.htm>. Acesso em: 28 fev. 2015.

TABANEZ, A.A.J.; VIANA, V.M.; DIAS, A.S. Consequências da fragmentação e do efeito de borda sobre a estrutura, diversidade e sustentabilidade de um fragmento de floresta de planalto de Piracicaba, SP. Revista Brasileira de Biologia, v. 57, n. 1, p. 47-60, 1992.

TABARELLI, M.; MANTOVANI, W. Gap-phase regeneration in a tropical montane forest: the effects of gap structure and bamboo species. Plant Ecology, v. 148, p. 149-155, 2000.

TOLEDO-ACEVES, T. Above and belowground competition between lianas and trees. In: SCHNITZER S. et al. (Ed.). Ecology of lianas. Hoboken: Wiley-Blackwell, 2014. p. 149-163.

UDULUTSCH, R.G.; ASSIS, M.A.; PICCHI, D.G. Florística de trepadeiras numa floresta estacional semidecídua, Rio Claro - Araras, Estado de São Paulo, Brasil. Revista Brasileira de Botânica, v. 27, n. 1, p. 125-134, 2004.

URBANETZ, C. et al. Existe efeito de borda no Cerrado do Valério? 2003. Disponível em: $<$ http://www.ib.unicamp.br/profs/fsantos/relatorios/ ne211r2a2003.pdf $>$. Acesso em: 24 mar. 2015.

VIANA, V.M; PINHEIRO, L.V. Conservação da biodiversidade em fragmentos florestais. Série Técnica IPEF, v. 12, n. 32, p. 25-42, 1998.

VIEIRA, I.C.G. Forest sucession after shifting cultivation in eastern Amazônia. 1996. 205 f. Thesis (Doctor of Philosophy) - University of Stirling, Stirling. 
SILVA, M.A. da et al. Cobertura de lianas e os efeitos sobre a regeneração de espécies arbóreas.

VILLANI, J.P. Zona de amortecimento do Parque Estadual da Serra do Mar - Núcleo Santa Virgínia: subsídio ao manejo sustentável dos fragmentos de Mata Atlântica. 2007. 81 f. Dissertação (Mestrado em Ciências Ambientais) Universidade de Taubaté, Taubaté.

WWF BRASIL. Mata Atlântica: oportunidades e desafios. Disponível em: <http://www.wwf.org.br/ informacoes/sala_de_imprensa/?39942/MataAtlntica-oportunidades-e-desafios $>$. Acesso em: 24 mar. 2015. 